\title{
Driving Web 2.0 Tool Adoption in Agricultural Education
}

\author{
Costopoulou C. ${ }^{1}$, Ntaliani M. ${ }^{2}$, Sideridis A. B. ${ }^{3}$
}

\section{N F O}

Received 16 Sept. 2010

Accepted 10 Dec. 2010

Available on-line 3 Apr. 2013

Responsible Editor: A. B.

Sideridis

\section{Keywords:}

Web 2.0, agricultural education, training.

\begin{abstract}
$\underline{\text { A B S T R A C T }}$
The new opportunities for collaboration, participatory content creation and communication offered through the advancements of Web 2.0, such as social networking, blogs, wikis, video sharing and other, are creating new learning models. In turn, tutors cannot ignore this trend and have to bear the responsibility of incorporating Web 2.0 tools in formal, informal, work-based and vocational education and approach their students in a very familiar and favourable way. In this context, this paper tries to highlight the need for enhancing tutors' skills and drive Web 2.0 tool adoption in educational practice. Thus, it draws upon the successful example of a European project regarding agricultural tutors' training on Web 2.0 tools. The challenge for all agricultural tutors is how to integrate Web 2.0 tools into current curricula and education.
\end{abstract}

\section{Introduction}

Although the term Web 2.0 has been used since 2005, the notion of Web 2.0 is not clarified yet (Constantinides and Fountain, 2008). A huge dispute has emerged upon this issue, reaching today with no consensus for a specific definition by the academic community and the business world. O'Reilly (2008), who is the inventor of the term, considers Web 2.0 the network as platform. Hoegg et al. (2006) perceive Web 2.0 as a philosophy-and not as a specific technology- that is structured by its users' common vision, reflects their knowledge and continuously adapts to changes in the environment. The overall aim of all Web 2.0 services is to mutually maximize the collective intelligence of the distributed knowledge among the participants.

The facts show that in the current times there has been noted a more mature diffusion of Web 2.0 applications, with blogging, photo and video-sharing, social networking and social gaming to have been adopted by 50\% of Internet users worldwide (Pascu, 2008). Their simplicity (Braun et al., 2007), the ease of use and capability of active participation and collaboration in content creation and editing through social networking, blogs, wikis, video sharing and other Web 2.0 tools has made them most popular among students. This reality has influenced the way students access information, communicate with others and learn, thus inducing new models of learning and teaching in formal, informal, work-based and vocational education. In turn, tutors face a significant challenge that lies in their ability to integrate Web 2.0 in their instructions and approach students in a very familiar and favourable way. Despite the substantial impact on formal education and training, Web 2.0 applications comprise a new discovery for schools and higher education (Weyant and Gardner, 2010), and neither of which has seized this new opportunity for enhancing learning and addressing their learners' needs (Redecker et al., 2009).

In this context this paper studies the current use and opportunities of Web 2.0 tools in education. It focuses on the Metaschool initiative regarding agricultural tutors' training on Web 2.0 tools, so as to

\footnotetext{
${ }^{1}$ costopoulou, Constantina

Informatics Laboratory, Agricultural University of Athens, 75 lera Odos Str., 11855, Greece

tina@aua.gr

${ }^{2}$ NTALIANI, Maria

Informatics Laboratory, Agricultural University of Athens, 75 lera Odos Str., 11855, Greece

ntaliani@aua.gr

${ }^{3}$ SIDERIDIS, Alexander B.

Informatics Laboratory, Agricultural University of Athens, 75 lera Odos Str., 11855, Greece

as@aua.gr
} 
enhance their skills and drive Web 2.0 tool adoption in educational practice. Therefore, the structure of the paper is as follows: in the next section a review on most popular Web 2.0 applications and their categorization, as well as their use in education are given. Then an overview of the Metaschool project and its objectives, as well as the main results from a training workshop at the American Farm School (AFS) are presented. Lastly, some conclusions and suggestions for further work are apposed.

\section{Web 2.0 Applications and Education}

In Web 2.0, a variety of applications is used to enable users to connect and collaborate with others, as well as create, find, categorize, share and reuse content. These applications provide different ways of interaction (e.g. email messages, blogs, file sharing and chat rooms) aiming at attracting different audiences.

Also, Web 2.0 websites mostly focus on friendship and personal relationships. There are also others that are of a specific geographic location, youth oriented, business and marketplaces, professional networks and networking for social development. Many of them are adapted to the mobile device environment customizing their layout to be browsed on small screen devices (such as personal assistants or phone browsers) (FAO, 2009).

Till today, there have been many categorizations of Web 2.0 applications according to their functionalities and features. FAO (2009) focuses on the support of work groups and collaboration, categorizing them as follows: groupware and collaboration tools; e-mail; listservs, mailing list and enewsletter; blogs and microblogs; video and photo sharing; podcasting; wikis; chats and instant messaging; voice chats and Voice Over IP (VoIP); video chats; and project management tools. Another categorization is used by Constantinides and Fountain (2008), who propose a basic classification based on application types, namely blogs, social networks, communities, forums/bulleting boards and content aggregators. Cain et al. (2009), consider as current popular Web 2.0 applications blogs, wikis, social networks, social videos, virtual worlds, podcasts, social bookmarking, document collaboration and repositories, aggregation applications (e.g. Really Simple Syndication-RSS feeds) and collaborative custom search engines.

Hoegg et al. (2006), distinguish Web 2.0 services according to the type they are provided into: (a) platforms or tools that help users to create, store, manage and share content, thus forming new communities. These platforms/tools offer services that according to the content type they support are characterized as directory services-enabling navigation activities-or technology centric servicesenabling individual content creation; (b) online collaboration tools, focusing on the efficiency enhancement of users' interplay, for example through online timetables, agendas and text processing; and (c) Community services, facilitation the social creation of content by users that have a common interest. In the following, the definitions of the most popular Web 2.0 applications are given:

- Wiki: is actually two things; a program that makes it exceptionally easy for anybody to edit Web pages and a philosophy regarding how users should go about that editing (Louridas, 2006).

- Podcast: (or non-streamed webcast) is a series of digital media files (either audio or video) that are released episodically and often downloaded through web syndication (Wikipedia, 2011a).

- Blogs: are web sites consisting of dated entries typically listed in reverse chronological order on a single page. They can be personal journals, market or product commentaries, or just filters that discuss current affairs reported elsewhere, participating in an online dialogue (Kolari et al., 2006).

- Media-sharing services: store user-contributed media (e.g. movies, photos, artwork, presentations), and allow users to search for and display content (Franklin and Van Harmelen, 2007). 
- Social bookmarking: is a method for Internet users to organize, store, manage and search for bookmarks of resources online. Unlike file sharing, the resources themselves aren't shared, merely bookmarks that reference them (Wikipedia, 2011b).

- Social networking sites: are web-based services that allow individuals to (1) construct a public or semi-public profile within a bounded system, (2) articulate a list of other users with whom they share a connection, and (3) view and traverse their list of connections and those made by others within the system (Boyd and Ellison, 2008).

The context and functionalities of such applications is in agreement with modern educational theories -constructivism and connectionism- and make them very attractive for teachers and learners (Ulrich et al., 2008). Although there is a long way for institutions, individuals and groups of teachers and students to grasp the opportunities of Web 2.0 there are very good examples. A study on the use of such applications at institutional level (Franklin and Van Harmelen, 2007), namely by universities in the United Kingdom, has shown that universities follow differing rationales and approaches to implementing Web 2.0 and that there are many open issues to be addressed, such as what types of tools to implement, how to encourage uptake and use and whether to host systems themselves, or rely on externally (commercially) hosted systems.

By searching the scholarly literature across many sources using the well-known search engine Google Scholar for the terms 'agricultural education' and 'Web 2.0', interesting conclusions have been derived. In particular, a small number of sources (including thesis, books, abstracts and articles) that contain the above terms has been found, most of which appear from 2008 and after. A similar search in other fields has produced totally different results. For example in the field of medicinal education the search has given more than 1000 resources, presenting the increased interest and widespread use of Web 2.0 (McLean et al., 2007, Sandars and Schroter, 2007, Boulos et al. 2006). This fact shows that although agriculture is a substantial economic sector there is a need for more profound research and practice for matching Web 2.0 with agricultural education so as to be tuned with current progress. In the following, a European project aiming at improving the in-service training of tutors and school Information and Communication Technology (ICT) staff through the effective use of digital content is presented.

\section{Metaschool Project Overview}

Metaschool (www.ea.gr/ep/metaschool) focuses on organisation, sharing, use and re-use of digital learning resources that can be accessed through online learning repositories. Analytically the aims of the project are the following: (a) adaptation, development, testing, implementation and dissemination of a training framework regarding metadata, learning resources, and learning repositories. The framework will include a curriculum, training activities with good in-school practices and supporting material; (b) development and implementation of strategies/ best practices for organising favourite/useful learning resources into personal portfolios of digital resources and setting up learning repositories at school or regional level; (c) proposal and testing of teaching methodologies/ pedagogical strategies regarding the use of digital learning resources in the context of the educational process for the subjects of Science and Agriculture; (d) promotion of a European virtual space for interconnecting school repositories and exchanging/sharing teaching resources; (e) organization of pilot training and validation activities for teachers/ ICT staff to develop methods/ strategies for taking advantage from organising learning resources into personal portfolios/ learning repositories and exchanging resources with teachers around Europe; (f) involvement of European organisations activating in school education and working on the promotion and best use of digital learning resources in the classroom; and (g) development of a structured and reusable set of guidelines and recommendations for supporting the creation and assessment of relevant teacher training programs.

Metaschool consortium comprises of nine partners with expertise and experience in various areas from six European countries, namely Greece, Belgium, Austria, Germany and the Czech Republic. The project improves teacher practice and propels new knowledge on Agriculture and Science based on the experience gained from the projects of Organic.Edunet (http://www.organic-edunet.eu) and COSMOS (http://www.cosmos-project.eu) respectively. As far as agriculture is concerned, the 
Metaschool project can support it in many ways. As mentioned above, environmental/agricultural education is one of its thematic areas. The particular area has been chosen because from one side numerous agricultural content and resources are available on the Internet allowing for a variety of instructional approaches, and from the other environmental/agricultural education has not been fully incorporated in the school curricula despite its significance to sustainable development.

A training framework comprised of 21 self-contained learning packages has been designed in the context of Metaschool. The learning packages are distinguished into three types: namely teaching and learning; ICTs in teaching and learning; and technical training. They are self-contained, offering flexibility and individual learning paths and taking into account different levels of ICT competence and experience with metadata and repositories. There are various ways of interconnecting the learning packages. There are learning packages providing introductory information that apply to teachers with little ICT experience, whereas others build on previous knowledge. Other learning packages refer to the most frequently mentioned application. One or two learning packages present good examples of practice to motivate teachers to use them directly in their classrooms. According the Metaschool training framework a series of training workshop have been organized in the participating countries. For the Greek case two workshops took place; first one focused on providing advanced training in using online repositories and metadata and is described in Costopoulou et al. (2010). In the following, the second workshop referring to Web 2.0 tools is presented.

\section{Training Workshop for Agricultural Tutors}

The Metaschool workshop took place at the premises of the AFS in Thessaloniki on May 252010. AFS is an independent, non-profit educational institution serving the rural population of Greece and the Balkans. It has been serving the sectors of food and agriculture since 1904, providing theoretical and practical education on farming and business practices that are economically viable, ecologically sound and socially responsible (AFS, 2010). It consists of the Secondary School, offering high school education with an additional practical focus on a full range of agricultural and technical subjects, the College of Agricultural Studies providing a BSc degree focusing on agribusiness, tourism, and environmental protection and the division of Lifelong Learning for transferring knowledge and skills on sustainable rural development through short courses, seminars, workshops and conferences.

The particular training has been realized through a one-day workshop. The participants consisted of 6 teachers, 3 college students and 2 ICT staff. All participants had access to a computer during the workshop, working alone, but also in groups of 2-3 persons for collaboration purposes when needed. It consisted of two phases. In the first phase the presentation and demonstration of the Web 2.0 tools, their functionalities, examples activity ideas, specific scenarios are described and their use in the classroom has been showcased to the teachers. By studying example scenarios given in the presentation, the teachers were asked to consider them as a basis to produce their own that will cover the topics they are teaching.

The workshop has been based on the use of two Metaschool learning packages. The first entitled "Web 2.0 Tools in Education". This learning package gives examples of existing Web 2.0 tools and the use of Wikipedia in classroom. Since AFS is an educational institution, more focus has been given to Wikis and the Moodle example (Modular Object-Oriented Dynamic Learning Environmentmoodle.org), a free open-source software package for producing Internet-based courses and web sites to support a modern social constructionist framework of education (Moodle, 2011). The ultimate goal is to provide teachers with the knowledge of these technologies and how to apply them in the classroom.

The second learning package entitled "Popular Social Tools and their Scenarios for Classroom Use" provides a description and examples on popular social tools and their usage. Such tools are Flickr (www.flickr.com), Youtube (www.youtube.com), Delicious (www.delicious.com), Slideshare (www.slideshare.net), Writeboard (writeboard.com) and other. Thus, teachers are enabled to use prominent Web 2.0 tools and take advantage of their capabilities in education. Specially designed scenarios provide teachers with actual evidence of the educational value of using such tools inside the 
classroom. The overall pedagogical objective is to familiarise the teachers with the use of popular social tools.

Then in the second phase, a twofold evaluation based on questionnaires took place, namely evaluation of the workshop and the presented learning packages. Moreover, personal interviews have been taken from the participants. According to the evaluation, the workshop has been considered by all participants as very successful. The presentations and demonstration have been considered much focused and engaging. The majority of participants believe that the workshop has much value for them and that it is much useful for their future instructions. A 75\% considers that the workshop can improve from much to very much their future instructions. Moreover, the majority is willing to attend another workshop. All participants believe that the workshop is much beneficial and is an important activity. More than half believe that the workshop was average to very good. The workshop leader's explanations were satisfactory to very good. More than $60 \%$ have enjoyed the workshop.

The majority believes that the knowledge presented was well known by them and they did not have much difficulty in using the tools/techniques shown. They found no difficulty in understanding content in the English language. The pace of the overall learning procedure was satisfactory. Also, the majority found no difficulty in following the content. The participants in general were familiar with the workshop content, except for a $25 \%$ that did not have any knowledge about it. They believe that they have learned very much knowledge that is helpful for improving their teaching/lessons. Thus, all of them are planning to use the tools presented during the workshop, as well as to introduce them to their colleagues. The smashing majority thinks that the workshop has met much their expectations.

According to the personal interviews, the workshop has given a variety of innovative ideas regarding the combination of Web 2.0 tools. One of the most useful things is uploading presentations and videos and giving the opportunity to the educational community to comment on them. The participants expressed their need for more time on: discussing educational scenarios and their realization in classroom through the presented tools, presenting detailed procedures examples for the advanced use of the tools, and hands-on sessions.

\section{Conclusions}

In spite of the use of Web 2.0 applications in students' everyday life, agricultural tutors have not yet much incorporated them in their lessons. Agricultural tutors need to recognize the potential of Web 2.0 in agricultural education. The challenge for all agricultural tutors is how to integrate Web 2.0 tools into current curricula and education. Common obstacles regard the lack of tutors' knowledge and skills on the applications and their use in educational scenarios. This paper has presented the successful example of the Metaschool project for enhancing agricultural tutors' skills on Web 2.0 tools. Metaschool training has provided a variety of innovative ideas on Web 2.0 tools for improving educational practice and has driven agricultural teachers' awareness and motivation towards them. As new concepts, such as mobile lifecasting, mobile socialcasting or mobile social streams and mobile micro-blogging are emerging (Pascu, 2008), relevant initiatives have to be supported so as the agricultural community to be aware of Web 2.0 technologies and their increasing role in providing agricultural information and education at any place and any time, following successfully the course of events. The potential of Web 2.0 for agricultural education activities will only be achieved if there is increased training in how to use this new approach. Careful thinking and research are still needed in order to find the best ways to leverage this approach to boost agricultural teaching/learning productivity.

\section{References}

AFS-American Farm School. Retrieved: 2010. http://www.afs.edu.gr/page/default.asp?la=2.

Boulos M., I.Maramba and S.Wheeler. 2006. Wikis, blogs and podcasts: a new generation of Web-based tools for virtual collaborative clinical practice and education. BMC Medical Education 6(41).

Boyd D. and N. Ellison. 2008. Social network sites: definition, history, and scholarship. Journal of ComputerMediated Communication 13:210-230. 
Braun S., A. Schmidt and A.Walter. 2007. Ontology maturing - a collaborative Web 2.0 approach to ontology engineering. In: Proc. of the Workshop on Social and Collaborative Construction of Structured Knowledge at the 16th International World Wide Web Conference (WWW07) Vol. 273 of CEUR Workshop Proceedings.

Cain J. and B. Fox. 2009. Web 2.0 and pharmacy education. American Journal of Pharmaceutical Education 73(7): 120.

Constantinides E. and S. Fountain. 2008. Web 2.0: conceptual foundations and marketing issues. Journal of Direct, Data and Digital Marketing Practice. Special Issue 9: 231-244.

Costopoulou C., N. Manouselis, M. Ntaliani and A. Tzikopoulos. 2010. Training agricultural tutors in digital learning repositories. In: Proc. ITAFFE'10-3rd International Congress on Information and Communication Technologies in Agriculture, Food, Forestry and Environment, 15-21.

FAO. 2009. Web 2.0 and Social Media Development. Information Management Resource Kit. http://www.imarkgroup.org/index_en.asp?m=0.

Franklin T. and M. Van Harmelen. 2007. Web 2.0 for content for learning and teaching in higher education. http://www.jisc.ac.uk/media/documents/programmes/digital_repositories/web2-content-learning-andteaching.pdf.

Hoegg R., R. Martignoni, M. Meckel and K. Stanoevska-Slabeva. 2006. Overview of business models for Web 2.0 communities. In:Proc. GeNeMe, 23-37. Universität St. Gallen Publisher.

Kolari, P., A. Java, T. Finin, T. Oates and A. Joshi. 2006. Detecting spam blogs: a machine learning approach. In: Proc. AAAI 2006, 16-20.

Louridas, P. 2006. Using wikis in software development. IEEE Software 23(2):88-91.

McLean R., B. Richards and J. Wardman. 2007. The effect of Web 2.0 on the future of medical practice and education: Darwikinian evolution or folksonomic revolution? Medical Journal of Australia 178:174-177.

Moodle. Retrieved: 2010; http://moodle.org/about.

O'Reilly, T.. 2008. Web 2.0: Compact definition? http://radar.oreilly.com/archives/2005/10/web-20-compactdefinition.html.

Pascu, K. 2008. An empirical analysis of the creation, use and adoption of social computing applications. IPTS exploratory research on the socio-economic impact of social computing. European Commission 2008.

http://ftp.jrc.es/EURdoc/JRC46431.pdf.

Redecker C., K. Ala-Mutka, M. Bacigalupo, A. Ferrari and Y. Punie 2009. Learning 2.0: the impact of Web 2.0 innovations on education and training in Europe. Euroepan Commission Joint Research Center. http://ftp.jrc.es/EURdoc/JRC55629.pdf.

Sandars J. and S. Schroter. 2007. Web 2.0 technologies for undergraduate and postgraduate medical education: an online survey. Post Graduate Medical Journal 83:759-762.

Ullrich C., K .Borau, H. Luo, X. Tan, L.Shen and R. Shen.2008. Why Web 2.0 is good for learning and for research: Principles and Prototypes. In: Proc. World Wide Web Conference International World Wide Web Committee (IW3C2), 705-714.

Weyant L. and C. Gardner. 2010. Web 2.0 application usages: implications for management education. Journal of Business, Society and Government 2(2): 67-78.

Wikipedia. Podcast. Retrieved: 2011a. http://en.wikipedia.org/wiki/Podcast.

Wikipedia. Social bookmarking. Retrieved: 2011b. http://en.wikipedia.org/wiki/Social_bookmarking. 